\title{
Autism spectrum disorder: impact of diagnosis on children's parents
}

\author{
Abstract \\ Objectives: To evaluate the impact of the diagnosis of autism in parents and to analyze its \\ determinants. \\ Methodology: Descriptive and correlational study. Used a sample of 138 parents enrolled \\ in three Portuguese Association for Developmental Autism Disorders. The questionnaire \\ included sociodemographic issues and a scale for assessing the impact of parenting.
}

Results: The impact of the diagnosis on the parents was moderate, but they are concerned about the future of their children, with the reactions and attitudes of the current society and lack of support / felt needs.

Conclusions: this study point to the promotion of intervention strategies by health professionals in order to minimize the negative impact that this diagnosis causes in families.
Volume 5 Issue 2 - 202I

\author{
Rosa Martins, Nélia Carvalho, Ruben \\ Carvalho, Susana Batista \\ Polytechnic Institute of Viseu, Portugal
}

Correspondence: Rosa Martins, Polytechnic Institute of Viseu, Portugal, Email rmartins.viseu@gmail.com

Received: April 07, 2020 | Published: March 29, 2021

Keywords: autism spectrum disorder, parents, impact of diagnosis, families, children

\begin{abstract}
Abbreviations: ASD, autism spectrum disorder; EAIDAP, evaluates the impact of the diagnosis in the parents; RA, reactions and attitudes; FI, family interaction; IAC, intrafamilial adaptation / changes at the family level; SAC, social adaptation/social changes; SPSS, software statistical package for social sciences
\end{abstract}

\section{Introduction}

Autism, currently called Autism Spectrum Disorder (ASD) by the American Psychiatric Association ${ }^{1}$ is a neurobehavioral syndrome that compromises motor development and psychoneurological impairment of the child's cognition, language, and social interaction. Although its etiology is still unknown, the current trend is to consider it as a syndrome of multicausal origin involving genetic, neurological and social factors. ${ }^{2}$ It is estimated that currently the worldwide prevalence of ASD is around 75 cases per 10,000 inhabitants, five times more frequent in boys than in girls. In Portugal, according to the Portuguese Federation of Autism (FPDA, 2017) although no exact statistical data is known, it is estimated that they are similar to the world data. The reasons that have been pointed out to justify the increase in the prevalence of the disease are diverse, however, they mainly focus on the changes made in the diagnosis criteria, the greater knowledge of the society in general and parents themselves about the occurrence of the syndrome, knowledge of the respective clinical manifestations and the emergence and development of specialized services in ASD. ${ }^{2}$ The literature on this subject is recurrent in the affirmation that early intervention is always the best solution for the progress of the child diagnosed with this disorder, since the symptomatology may be variable and the intervention programs as well. ${ }^{3}$ Back in 2008 Xavier emphasized aspects relating to families, highlighting the importance of the involvement of parents of autistic children, since in the history of mental health movement, there are few examples of a diagnostic category as misunderstood as infantile autism.

It is understood that when planning the coming of a child the couple expects to have a perfect child, without anomalies, with healthy development and growth, becoming an adult with autonomy.
It can even be said that the birth of a child is the formulation of a new life cycle, which is idealized by parents and the whole family. However, this does not always happen and the birth of a child outside the "parameters of normality" brings a new reality to the family, since the child with developmental changes also began to be born in the parents' thinking, imagination and fantasy, as a perfect child. ${ }^{4}$ The confrontation with this reality, causes in the family an emotional impact that will be in the first moment of great disillusionment, losing in consequence, the established relational objectives, subsisting feelings, emotions and attitudes different from those of the other parents. In fact, the birth expected by the families as being a moment of great joy, quickly becomes moments of pain, tears, frustration, anguish, fear, insecurity and many other feelings. ${ }^{5}$ These authors tell us that for these children to have a place in their families they have to be "born again", meaning that they have to be idealized again by their parents, because parental re-idealization is a fundamental development task. This (re-idealization) depends on two factors: beauty and hope. The beauty makes the parents like their child and let them captivate aesthetically and emotionally for him and hope allows to create future projects and ideas.

However, this process will only be possible when the parents have overcome the mourning of the loss of the dreamed baby. Parents' reaction patterns are differentiated and have often been compared to the feelings described in the stages of mourning, by Elisabeth KüblerRoss (denial, anger, bargaining, depression, and acceptance). In the opinion of Dantas et al. ${ }^{4}$ the stages of mourning depend on families, not always happening in the same order and may appear combined or omitted, according to sociocultural formation, concepts and common sense about disability. Gomes ${ }^{6}$ tells us that mourning takes place in three phases: the knowledge of the diagnosis, the adaptation process and the advanced phase of the disease. In the first phase, the family, when knowing the diagnosis, manifests a reaction of shock or emotional impact. In a second step, the family recognizes the situation, yet faces feelings such as anxiety, frustration, rebellion and guilt, feeling powerless to the diagnosis. And finally, the denial stage can happen, where families do not believe in the diagnosis of 
their child and seek other doctors in the hope of finding a different opinion. In the second phase the acceptance of the deficiency begins. The family is already able to talk about the problem and begins the reorganization of ideas, developing a learning experience with the child with a disability. In the third phase, however, there is a desire not to express feelings, yet they are present, either through the void that is not known to fill or by the feelings of malaise and guilt that persist. In fact, regardless of the phases and forms of manifestation of mourning, it is consensual among authors who face confrontation with disability parents experience shock, fear, pain, anxiety for the future, loss, guilt and denial. ${ }^{3}$

The shock is characterized by a disruption of the balance, to bring the usual emotional states, showing itself through feelings of powerlessness and helplessness. The intense emotional reactions are those of sadness, anger and anxiety. Adaptation happens when parents begin to reorganize their lives according to their child and trying to find the best way to help them. In synthesis we can say that each family has its own characteristics, they are different from each other and react in different ways. Studies show that many families can reach the stage of adaptation and others do not. The addition of these phases often depends, according to Gomes ${ }^{6}$ the severity and type of disability, meaning that every family attributes to the disorder, the socio-cultural family level, character, personality, ability to adapt to each and still by personal experiences. This study is justified by the scientific relevance of the topic and the possible contributions it will provide to health professionals and academics regarding the understanding of the dialogical relationship between the health professional and the family regarding the diagnosis of childhood autism and its repercussion in family relationships. Thus, the objective of this research was to analyze the context of the diagnosis of autism and its impact on family relationships. Reflection made and scientific relevance of the theme emerge the following questions: "What is the impact of the disorder of autism diagnosis in children's parents? What factors (sociodemographic and context) are associated with this Impact? In order to answer these questions the objectives of the study are to evaluate the impact of the diagnosis of autism disorder in the parents of children with this syndrome and to identify factors associated with this impact.

\section{Material and methods}

Quantitative,cross-sectional, descriptive and correlational study. A non-probabilistic sample was used for convenience, consisting of 138 parents of children diagnosed with autism spectrum, enrolled in three Portuguese Associations for Developmental Disorders and Autism in the central and northern regions of Portugal. Data collection took place between September 2016 and March 2017, and the instrument used included questions of socio-demographic characterization (concerning parents and children with ASD), questions of pre and neonatal context, questions regarding the way in which parents became aware of disorder and a scale that evaluates the impact of the diagnosis in the parents (EAIDAP). This scale was adapted and validated for the Portuguese population by Mónica Febra in 2009 and consists of 72 items (with responses type Lickert) that are subdivided into 7 dimensions: Feelings and emotions to know the problem of your child (FE), Current reactions and attitudes (RA), Family interaction (FI), Intrafamilial adaptation / changes at the family level (IAC), Social adaptation/social changes (SAC), Expectations regarding the future (EF) and Reactions to support / needs (RSN). Lower scores on the scale correspond to a greater impact on parents. Data collection was performed by the investigator, the data were released on a basis and its treatment was performed using the software Statistical Package for Social Sciences (SPSS) version 20.0 for Windows and Microsoft Word, and was processed using descriptive statistics and inferential statistics. All procedures were carried out according to strict ethical conduct (with authorizations by the Institution Officers and respective Ethics Committees), presentation of informed consent, ensuring the anonymity and confidentiality of the data collected, respecting the principles of the Helsinki Declaration.

\section{Results}

The sample of this study (Table 1) consists of 138 parents, mostly female $(65.2 \%)$, with a mean age of 41.16 years. The ages ranged from 24 to 62 years, with younger mothers $(M=39.31$ than parents $(\mathrm{M}=44.63)$ with statistically significant differences $(\mathrm{t}=2.594, \mathrm{p}=0.012)$. These parents are mostly employed (68.3\%), earn a monthly income of more than $€ 1000$ (52.8\%) and have medium and higher education qualifications $(44.6 \%)$. The families are mainly of the nuclear type, in which the father and mother are married or living as unmarried couples $(84.1 \%)$. A large proportion of families live in urban areas (70.1\%) and live in isolated housing (53.6\%); Children with ASD have ages ranging from 2 to 19 years, with a mean age of 9.71 years. There are more boys (78.3\%) than girls $(21.7 \%)$, whichever boys eight and more years old. Girls 'academic qualifications are lower than boys', because the majority (76.2\%) still attend pre-school education. We observed that $43 \%$ of the children are single children, $40.6 \%$ have 1 sibling and only $17.4 \%$ have two and more siblings, all living in their parents' households. The majority (89.6\%) of these children are the result of a normal pregnancy and of a birth within the expected time (term), however we found that in $57.1 \%$ a dystocic birth occurred (requiring medical intervention) and only $44,9 \%$ was normal (normal), although statistical differences were not significant $\left(\mathrm{x}^{2}=0.383, \mathrm{p}=0.536\right)$. The results on the diagnosis of autism show that this was known by most parents $(81.2 \%)$ a few years later, $11.6 \%$ knew it a few months later and only $7.2 \%$ knew it after birth. The information was mostly given $(81.2 \%)$ by the doctor and only a small group (18.8\%) was alerted by other sources (teachers, family, friends, themselves). When the diagnosis was transmitted the parents were mostly (79.7\%) accompanied and only $20.3 \%$ reported being alone. The women $(28.9 \%)$ were alone in more cases than the men $(4.2 \%)$, and this difference was statistically significant $(x 2=5.915, \mathrm{p}=0.015)$.

Table I Statistics related to age and gender of the parents

\begin{tabular}{lllllllll}
\hline Age/ Gender & N & Min & Max & M & SD & CV (\%) & SK/erro & K/erro \\
\hline Male & 48 & 33 & 62 & 44.63 & 9.03 & 20.233 & 2,722 & 1,184 \\
Female & 90 & 24 & 59 & 39,31 & 7,573 & 19,265 & 2,862 & 0,859 \\
Total & 138 & 24 & 62 & 41,16 & 8,438 & 20,500 & 3,896 & 2,667 \\
\hline
\end{tabular}


The data on the impact of the diagnosis of autism in the parents are expressed in Table 2, and the more intense values translate into greater impact. We can generically affirm that the overall impact of the diagnosis was moderate, $(\mathrm{M}=2.94, \mathrm{SD}=0.281)$. The lowest values $(\mathrm{M}=2.348, \mathrm{SD}=0.566)$, to the current reactions and attitudes $(\mathrm{M}=2,697, \mathrm{SD}=0.448)$, and to the perceived supports / needs $(\mathrm{M}=2.744, \mathrm{SD}=0.472)$. Conversely the higher values and therefore with less impact are associated with dimensions adapted and changes on the social level $(\mathrm{F}=3.296, \mathrm{SD}=0.660)$, adaptation and changes the family level $(\mathrm{F}=3.203, \mathrm{SD}=0.496)$, feeling, and emotions $(\mathrm{M}=3,097$, $\mathrm{SD}=0.664)$, and family interaction $(\mathrm{F}=3.012, \mathrm{SD}=0.304)$. In the analysis of association between variables, we found that the parents who reported the greatest overall impact in relation to the diagnosis of autism were: males $(\mathrm{p}=0.021)$, single status $(\mathrm{p}=0.020) 0.003)$ and with lower literacy $\left(1^{\mathrm{st}} / 2^{\text {nd }}\right.$ cycles $)(\mathrm{p}=0.034)$. Also, those parents who had a dystocic birth $(\mathrm{p}=0.040)$, who followed a risk pregnancy $(\mathrm{p}=0.036)$ and who were alone at the time of the news $(p=0.038)$ reported a greater impact. However, the age, place of residence, monthly income and the person who reported on the diagnosis showed no significant correlation ( $p>0.05$ ) with the impact of the diagnosis of autism caused in the parents of children with ASD.

Table 2 Statistics related to the impact of the diagnosis of autism in parents

\begin{tabular}{lccccccc}
\hline Impact of the diagnosis of autism & Min & Max & Mean & SD & CV (\%) & SK/erro & K/erro \\
\hline Feelings and emotions & 1,56 & 4,44 & 3,097 &, 664 & 21,44 &, 53 &,- 91 \\
Current reactions and attitudes & 1,69 & 3,77 & 2,697 &, 448 & 16,61 & 1,30 &, 25 \\
Family interaction & 2,45 & 4,00 & 3,012 &, 304 & 10,09 & 2,35 & 3,37 \\
Adaptation and changes at the family level & $\mathrm{I}, 83$ & 4,25 & 3,203 &, 496 & 15,49 &,- 56 &, 25 \\
Social adaptation and changes & $\mathrm{I}, 7 \mathrm{I}$ & $4,7 \mathrm{I}$ & 3,296 &, 660 & 20,02 &,- 67 &,- 69 \\
Expectations about the future & $\mathrm{I}, 50$ & 4,67 & 2,348 &, 566 & 24,11 & 2,89 & 4,45 \\
Reactions to felt support / needs & $\mathrm{I}, 86$ & 4,04 & 2,744 &, 472 & 16,03 &, 57 & $\mathbf{1 , 1 5}$ \\
Overall impact of autism diagnosis & 2,34 & 4,07 & 2,942 &, 281 & 9,55 & 2,53 & 5,33 \\
\hline
\end{tabular}

\section{Discussion of results}

We realized with this study that parents moderately felt the impact of the diagnosis of autism: Some still could not overcome the initial shock, showing feelings such as anguish, sadness, revolt, fatigue and even discouragement. These conclusions corroborate those of Pinto et $\mathrm{al}^{2}{ }^{2}$ when they affirm that the family usually goes through a sequence of stages, ranging from impact, denial, mourning, external focus and closure to the time of the disclosure of the disease or chronic syndrome, which are associated to difficult and even conflicting feelings. However, we also feel that they develop coping strategies through active denial, focus on problem, positive thinking and recourse to religiosity, as in the studies of Hastings et al. ${ }^{7}$ One of the main concerns of parents is the future of their children. It is a fact that overcomes the conclusions of Febra ${ }^{8}$ Araújo ${ }^{9}$ and Franco et al. ${ }^{5}$ emphasizing the uncertainties and anxieties that the children's future prediction causes. They suggest as strategy the re-idealization of the child in search of a sense of the existence of a future with several answers. On the other hand Pinto et al. ${ }^{2}$ tell us that positive or negative expectations about the development and future of the child may be influenced by the understanding of the information and resources offered, necessary for the child's good development. The reactions and attitudes of society in general in the face of the disorder and the support / needs felt by the families are also a concern of the parents, referring to the need to strengthen the role of society, as it is still difficult to access rehabilitation services, integrate the education system or labor market or participate in social activities. ${ }^{10}$

We should also highlight the positive impacts that we have found in this study, mainly related to the dimensions of adaptation and social changes, adaptation and changes at the family level, feelings and emotions and family interaction. Data are similar to those of King et al. ${ }^{11}$ to detect feelings of optimism, acceptance, adaptation, hope and control, revealing the strength and resistance of families to the adversities of life. In fact many of these parents are already accepting the diagnosis and as Silva et al., ${ }^{3}$ tells us, accepting the diagnosis means that the parents are ready to work for the child and the child in order to meet their special needs. The studies carried out by Hastings et al., ${ }^{7}$ have shown that families of higher socioeconomic level and education have a more cohesive relationship, favoring the union and consecutively the family interactions and the family adaptations to changes. As the socioeconomic level and the qualifications decrease the capacity to overcome the problem and to evaluate the impact of the diagnosis of the deficiency in their relation is smaller. These findings are corroborated by our results as the families in our sample also had monthly income and higher education.

When analyzing the sociodemographic factors influencing the impact of the diagnosis, we find the gender (male), marital status (single), type of families (single-parent) and schooling (low): these findings reinforce the investigations of other authors with similar correlations . In this regard, Pereira ${ }^{12}$ states that single parent families are more vulnerable, needing more specific support to respond to the needs their child requires. Xavier ${ }^{13}$ adds that in families where the child (with ASD) does not occupy the first place in the fratria, the impact is usually less aggressive. Also important were the pre and neonatal context factors, including the form of communication of the disorder, since the impact was higher in parents who had a dystocic birth, who followed a pregnancy at risk and who were alone at the time it was given the news. It can be seen that parents accompanying a risky pregnancy or dystocitis have become more vulnerable due to the personal, family and social changes that these situations cause. Likewise, the form and circumstances (physical and social) in which the news is received are decisive in understanding the problem. Pinto et al., ${ }^{2}$ emphasize the importance of the moment, stating that the diagnostic revelation of autism becomes a complex, delicate and challenging moment for the family, as well as for the health professionals responsible for this mission. The physical environment associated with the other circumstances (support from family and friends) related to the news can positively interfere in the minimization of family suffering. ${ }^{14}$ 


\section{Conclusion}

From the results of this research we realized that the impact of the diagnosis of autism disorder in the parents of children with ASD is moderate. The values ranged from low impact to high impact with important repercussions in the family context. The moment of diagnosis constituted a stressful and striking event that varied between shock, sadness, suffering and denial. The delay in establishing the clinical diagnosis was visible since only $7.2 \%$ of the parents knew it after birth creating false expectations about the signs and symptoms presented. The employability, favorable socioeconomic conditions and high schooling of our sample contributed positively to the impact mentioned. The manifestations of a more marked impact are associated with parents' expectations about their children's future, the reactions and attitudes of today's society, and the lack of support / felt needs, are justifiable feelings of fear of the unknown future, social isolation and rejection of the still existing society, since the stigma and segregation given to a child with a disability are unpleasant effects, especially when they are experienced within the family. Acceptance, adaptations and negotiation of new roles in the family and in the social environment are also visible due to the low impact associated with the dimensions of adaptation and changes at the family and social level, feelings and emotions, and family interaction itself. The circumstances surrounding the development of pregnancy and childbirth and the way in which the diagnosis was conveyed were negative determinants of impact. These data point us to the need for greater vigilance and monitoring by health professionals that corresponds to the wishes of the family members involved. Also, the transmission of bad news must be "treated with tweezers" because given alone to the familiar recipient, without him feeling supported and accompanied by other family or friends makes that moment even more arduous. We believe that the study's importance, and implications for the practice of health professionals, are clear in the study. To contribute to the resizing of the knowledge about the peculiarities of autism disorder and reflexes within the family and social environment, was our intention reiterated in the development of the study.

\section{Acknowledgments}

None.

\section{Conflicts of interest}

The author declares there is no conflcit of interest.

\section{References}

1. American Psychiatric Association. DSM-V: Statistical diagnostic manual for mental disorders. (5th ed.). São Paulo: Medical Arts. 2013.

2. Pinto RNM, Torquato IMB, Collet N, et al. Autismo infantil: Impacto do diagnóstico e repercussões nas relações familiares. Revista Gaúcha de Enfermagem. 2016;37(3):e61572.

3. Silva EN, Oliveira LA. Autismo: Como os Pais reagem frente a este diagnóstico? Unoesc \& Ciência ACBS. 2007;8(1):21-26.

4. Dantas M, Collet N, Moura F, et al. Impacto do diagnóstico de paralisia cerebral para a família. Revista Texto Contexto Enfermagem. 2013;19(2):229-237.

5. Franco V, Apolónio AM. Desenvolvimento, resiliência enNecessidades da família com crianças deficiêntes. Revista Ciência Psicológica. 2015;8:112 .

6. Gomes AM. A importância da resiliência na (re)construção das famílias com filhos portadores de deficiência: O papel dos profissionais da educação/reabilitação. Revista Saber (e) Educar. 2012;11:49-71.

7. Hastings R, Kovshoff H, Ward N, et al. Systems analysis of stress and positive perceptions in mothers and fathers of pre-school children with autism. Journal of Autism and Developemental Disorders. 2015;35(5):635-644.

8. Febra M. Impacto do diagnóstico da deficiência mental na família (Dissertação de mestrado, Universidade de Coimbra). 2009.

9. Araújo JA, Leitão, EMP. Communicating bad news: pious lying or careful sincerity. Revista HUPE. 2012;11(2):58-62.

10. Levenson D. Autism in siblings often caused by different faulty genes, study says. American Journal of Medical Genetics. 2015;167(5):5-14.

11. King G, Baxter D, Rosenbaum P, et al. Belief systems of families of children with autism spectrum disorders or down syndrome. Focus on Autism and Other Developmental Disabilities. 2016;24(1):50-64.

12. Pereira M. Pais de alunos autistas: Relatos de expectativas, experiências e concepções em inclusão escolar. (Dissertação de mestrado, Universidade Católica de Brasília).

13. Xavier R. Familias com filhos portadores de deficiencias: Quotidiano e representações. (Dissertação de mestrado, Insituto Universitário de Lisboa). 2008.

14. Federação Portuguesa de Autismo. Federação Portuguesa de Autismo. Lisboa. FPA. 2017. 